\title{
Modification of Vietnam Natural Rubber via Graft Copolymerization with Styrene
}

\author{
Tran Anh Dung, ${ }^{a}$ Nguyen Thi Nhan, ${ }^{a}$ Nghiem Thi Thuong, ${ }^{a}$ Phan Trung Nghia, ${ }^{a}$ \\ Yoshimasa Yamamoto, ${ }^{b}$ Kenichiro Kosugi, ${ }^{c}$ Seiichi Kawahara ${ }^{c}$ and Tran Thi Thuy ${ }^{*, a}$ \\ ${ }^{a}$ School of Chemical Engineering, Hanoi University of Science and Technology, No.1 Dai Co Viet \\ street, Hai Ba Trung District, Hanoi, Vietnam \\ ${ }^{b}$ Deparment of Materials Science and Engineering, National Institute of Technology, Tokyo College, \\ 1220-2 Kunugida-machi, 193-0997 Hachioji, Tokyo, Japan \\ 'Department of Materials Science and Technology, Falculty of Engineering, Nagaoka University of \\ Technology, 1603-1, Kamitomioka-machi, 940-2188 Nagaoka, Niigata, Japan
}

\begin{abstract}
Graft copolymerization of styrene onto deproteinized natural rubber (DPNR) using tert-butyl hydroperoxide (TBHPO) and tetraethylene pentamine (TEPA) as redox initiator have been investigated. The effects of initiator and monomer concentration on conversion and grafting efficiency were studied. The dynamic mechanical and thermal properties of the graft copolymer were investigated over the wide range of temperatures. It is shown that a high value of storage modulus for the graft copolymer, which was about 25 times as high as that of DPNR, was achieved. The graft copolymer (DPNR-graft-PS) showed the outstanding tensile strength and stable thermal properties. These enhancements were attributed to the interaction between NR and polystyrene as a result of the graft copolymerization. Morphology observation by transmission electron micrograph (TEM) revealed that the core-shell arrangement of the DPNR-graft-PS with about $30 \mathrm{~nm}$ in thickness of polystyrene nano-layer was achieved.
\end{abstract}

Keywords: graft copolymer of styrene, Vietnam natural rubber, thermal properties, dynamic mechanical property, morphology

\section{Introduction}

Natural rubber (NR), obtained from Hevea brasiliensis, contains $93-95 \%$ of cis-1,4-polyisoprene. ${ }^{1}$ It is an unsaturated elastomer with many superior properties such as high strength, outstanding resilience, and high elongation at break. ${ }^{2}$ However, NR lacks in some properties such as oil and weather resistances. Moreover, the presence of the unsaturation of carbon-carbon double bonds in the NR backbone causes easy degradation when NR is exposed to sunlight, ozone, UV radiation and air, especially at high temperature. ${ }^{3}$ Therefore, chemical modification of NR is needed to overcome the disadvantages and to achieve more desirable properties. The chemical modification not only improves the interaction between the blend components but also compensates some of NR drawbacks such as its resistance to ageing and to solvents or its gas impermeability. ${ }^{4}$

Many types of chemical modification have been used, such as chlorination, ${ }^{5}$ epoxidation, ${ }^{6}$ hydrogenation, ${ }^{7}$ and

*e-mail: thuy.tranthi3@hust.edu.vn grafting. ${ }^{8,9}$ Among these, grafting is one of the most attractive techniques. Several common vinyl monomers have been reported for grafting modifications of NR such as: acrylonitrile (AN) ${ }^{10}$ methyl methacrylate (MMA), ${ }^{11}$ maleic anhydride (MA), ${ }^{3}$ and styrene ${ }^{12,13}$ Recently, styrene has become an attractive monomer to improve mechanical and thermal properties of NR because of the aromatic structure in the monomer molecule. In our previous works, graft copolymerization of styrene onto NR latex has been carried out, in which the mechanical properties, i.e., tensile strength, was significantly improved by the formation of polystyrene nanomatrix. ${ }^{13,14}$ However, thermal and dynamic mechanical properties of the graft copolymer of styrene have not been reported fully, yet. Wongthong et al. ${ }^{3}$ reported that graft copolymerization with maleic anhydride (MA) brought about the improvement of thermal stability of the graft copolymer. Therefore, such improvement is expected to be observed after graft copolymerization of styrene onto NR.

In previous works, ${ }^{13-16}$ it has been found that the grafting reaction on the naturally-obtained NR latex is not efficient 
and is suppressed by the presence of proteins in the NR latex. The protein can act as free-radical scavenger and terminate the free-radical species involved in the grafting reaction. Besides, protein also causes formation of gel or a branched network in NR. ${ }^{17,18}$ Consequently, it is very crucial to remove proteins from the NR latex before carrying out the chemical modification.

The removal of proteins could be performed in latex stage by enzymatic deproteinization to remove proteins present on the surface of the rubber particle as a dispersoid. In this method, the nitrogen content of NR was reduced to less than 0.02 wt. $\% .{ }^{19}$ However, it is time consuming, that is more than $24 \mathrm{~h}$ of the incubation, and the remaining proteins, peptides, or amino acid sequences can cause intraoperative anaphylactic reactions of hypersensitive patients of allergy. ${ }^{18}$ We established the novel procedure for removal of protein from NR by incubating NR latex with urea followed by three times of washing by centrigufation. ${ }^{18}$ In this method, urea was used as an effective denaturing agent, resulting in the decrease of nitrogen content of NR from 0.38 to $0.02 \%$, just for about one hour of incubation. ${ }^{20}$

Redox initiator is composed of two components. One is a hydrophobic oxidizing and other one is a hydrophilic reducing agent, for example, potassium persulfate $\left(\mathrm{K}_{2} \mathrm{~S}_{2} \mathrm{O}_{8}\right)$-sodium thiosulfate $\left(\mathrm{Na}_{2} \mathrm{~S}_{2} \mathrm{O}_{3}\right),{ }^{21}$ cumene hydroperoxide (CHPO)-tetraethylene pentamine (TEPA), ${ }^{12}$ and tert-butyl hydroperoxide (TBHPO)-TEPA..$^{22}$ Compared with others, TBHPO-TEPA initiator is the best redox system for the graft copolymerization of vinyl monomer onto NR latex because of the reaction in an ambient temperature, which gives the high grafting efficiency. ${ }^{21,22}$

In the present work, we aim at studying the thermal and dynamic mechanical properties as well as a morphology observation of the graft copolymer of styrene with NR. First, graft copolymerization of styrene onto deproteinized natural rubber (DPNR), which is prepared from Vietnam NR latex, is studied to obtain high conversion and high grafting efficiency using TBHPO-TEPA as a redox initiator. Then, characterization is performed by NMR spectroscopy to confirm the structure of the graft copolymer. The mechanical, thermal, and dynamic mechanical properties as well as morphology of the graft copolymer are investigated.

\section{Experimental}

\section{Chemicals}

High ammonia NR latex containing about $60 \%$ of dry rubber content (DRC) was provided by Vietnam Rubber Latex Co., Ltd. (Vietnam). Sodium dodecyl sulfate (SDS; 99\%) was purchased from Chameleon Reagent (Japan). Urea
(99.5\%) was obtained from Nacalai Tesque (Japan). tertButylhydroperoxide (TBHPO) and tetraethylene pentamine (TEPA) were purchased from Sigma-Aldrich (Netherland). $\mathrm{OsO}_{4}$ aqueous solution (4\%) was obtained from Heraeus Chemicals Sa (Pty) Ltd. (Japan). Other chemical products were also purchased from Sigma-Aldrich.

\section{Preparation of DPNR latex and graft copolymer}

DPNR was prepared by incubation of the latex with 0.1 wt. \% urea and $1 \mathrm{wt} . \%$ SDS at room temperature for $60 \mathrm{~min}$ followed by centrifugation at $10000 \mathrm{rpm}$ for $30 \mathrm{~min}$. The cream fraction was re-dispersed in $1 \mathrm{wt} \%$ SDS solution, and it was washed twice by centrifugation to prepare the DPNR latex with $60 \mathrm{wt}$ \% DRC. The resulting DPNR latex contained about $0.1 \mathrm{wt} . \%$ SDS. ${ }^{18}$

The recipes for graft copolymerization are presented in Table 1. Two series of experiments, A and B, were conducted to investigate the effect of initiator and monomer concentration on the graft copolymerization, respectively. The procedure for the graft copolymerization was carried out according to the following steps. The DPNR latex was first introduced into a $500 \mathrm{~cm}^{3}$ glass reactor equipped with a mechanical stirrer. The latex was first stirred under a stream of saturated nitrogen obtained by bubbling inert gas through the latex for $60 \mathrm{~min}$ at $400 \mathrm{rpm}$ to remove the dissolved oxygen in the latex. Afterwards TBHPO-TEPA were added as an initiator followed by styrene as a monomer. The reaction was carried out by stirring the latex at $400 \mathrm{rpm}$ for $2.5 \mathrm{~h}$ at room temperature.

The unreacted styrene was removed by using a rotary evaporator under reduced pressure. The product was put in a glass Petri dish and dried in a vacuum oven at $50{ }^{\circ} \mathrm{C}$ for more than a week. Soxhlet extraction was performed to purify the product. Free-polystyrene was extracted with acetone/2-butanone 3:1 mixture under nitrogen atmosphere in the dark for $24 \mathrm{~h}$, followed by drying under reduced pressure for a week.

The styrene conversion, grafting efficiency (GE) were measured by gravimetric method, according to the following expressions:

$$
\begin{aligned}
& \text { Styrene conversion }(\%)=\frac{\text { weight of polystyrene in gross copolymer }}{\text { weight of monomer }} \times 100 \\
& \text { GE }(\%)=\frac{\text { weight of polystyrene linked to natural rubber }}{\text { weight ofpolystyrene in gross copolymer }} \times 100
\end{aligned}
$$

\section{Characterization}

${ }^{1} \mathrm{H}$ nuclear magnetic resonance ( ${ }^{1} \mathrm{H}$ NMR) spectra were performed with a JEOL JNM-ECA $400 \mathrm{MHz}$ spectrometer 
Table 1. Typical recipes and conditions used for the graft copolymerization

\begin{tabular}{lcc}
\hline Ingredients and conditions of reaction & \multicolumn{2}{c}{ Series A } \\
\hline Latex / g & 200 & 200 \\
Initiator system / $\left(10^{-5} \mathrm{~mol} \mathrm{~g}^{-1}\right.$ dried rubber $)$ TBHPO:TEPA $=1: 1$ & $1,2,3,3.5,4,4.5$ \\
Styrene/ $\left(10^{-3} \mathrm{~mol} \mathrm{~g}^{-1}\right.$ dried rubber $)$ & 1.5 & 3.5 \\
Reaction temperature $/{ }^{\circ} \mathrm{C}$ & 30 & 2.5 \\
time reaction $/ \mathrm{h}$ & 30 \\
\hline
\end{tabular}

using the samples which were dissolved in deuterated chloroform.

The glass transition temperature $\left(\mathrm{T}_{\mathrm{g}}\right)$ of NR and the graft copolymer were measured by differential scanning calorimetry (DSC) using a DSC 7020 Exstar analyzer. The samples were cooled down to $-150^{\circ} \mathrm{C}$ using liquid nitrogen and heated up to $150{ }^{\circ} \mathrm{C}$ at a constant rate of $20^{\circ} \mathrm{C} \mathrm{min}^{-1}$. Thermal gravimetric analysis (TGA) experiments were performed using a Shimadzu DTG-60H analyzer using a heating rate of $10{ }^{\circ} \mathrm{C} \mathrm{min}^{-1}$ under an argon atmosphere and a temperature scan of $30-800{ }^{\circ} \mathrm{C}$.

Tensile measurement was conducted using a Toyo Seiki Strograph VG10E according to JIS K6251. Film samples were cut with a Dumbbell-shaped No. 7. The crosshead speed was $200 \mathrm{~mm} \mathrm{~min}^{-1}$.

The dynamic mechanical properties (DMA) were determined using an Anton Paar Physica MCR 302 analyzer. Measurements of the storage modulus, the loss modulus, and the damping factor $\tan \delta$ were performed in the temperature range of -70 to $140{ }^{\circ} \mathrm{C}$ and frequency range of 0.1 to $10 \mathrm{~Hz}$. Parallel plate geometry of $12 \mathrm{~mm}$ diameter was used. The measurement was carried out within the range of linear viscoelasticity.

The transmission electron micrograph (TEM) observation was performed with a JEOL JEM-2100 at accelerating voltage of $200 \mathrm{kV}$. The ultrathin sections of samples were cut with a Reichert-Nissei ULTRACUT N/C S at a temperature of $-90^{\circ} \mathrm{C}$. The sections with thickness of about $100 \mathrm{~nm}$ were stained with $\mathrm{OsO}_{4}$ vapor in about $10 \mathrm{~min}$.

\section{Results and Discussion}

\section{Chemical structure of the graft copolymer}

The confirmation of the chemical structure of the graft copolymer (DPNR-graft-PS) was obtained from ${ }^{1} \mathrm{H}$ NMR as presented in Figure 1. The characteristic signals of cis-1,4-isoprene units appear at 1.67, 2.03, and $5.12 \mathrm{ppm}$, which could be attributed to the methyl, methylene, and unsaturated methine protons, respectively. ${ }^{23}$ Moreover, the peaks at 6.5-7 ppm were attributed to the aromatic protons of styrene in the DPNR-graft-PS copolymer.

\section{Parameters affecting grafting efficiency}

The effect of TBHPO-TEPA initiator over the range of 1 to $5 \times 10^{-5} \mathrm{~mol} \mathrm{~g}^{-1}$ of dried rubber was investigated. The results were presented in Figure 2. It was found that both the conversion and the grafting efficiency were dependent on the initiator concentration and the values were the highest at the initiator concentration of $3.5 \times 10^{-5} \mathrm{~mol} \mathrm{~g}^{-1}$ dried rubber, which is 91 and $75 \%$, respectively. The increase in the initiator concentration resulted in more active radicals being produced on NR particles. Hence, the chance of the interaction of rubber macro radicals with each other to form gel or a branched network increases. However, low initiator concentration will not generate enough radicals to activate the NR particles to obtain high conversion and high grafting efficiency. The optimum initiator concentration, therefore, is determined to be $3.5 \times 10^{-5} \mathrm{~mol} \mathrm{~g}^{-1}$ dried rubber.

The effect of styrene monomer in a range of 0.5 to $3.5 \times 10^{-3} \mathrm{~mol} \mathrm{~g}^{-1}$ of dried rubber was investigated. The results are shown in Figure 3. It can be seen that the grafting efficiency increases with increasing content of styrene up to $1.5 \times 10^{-3} \mathrm{~mol} \mathrm{~g}^{-1}$ of dried rubber. This suggested that graft copolymerization may occur only on the surface of the latex particles because of the immiscibility between styrene and NR particles. This may be due to a deactivation and chain transfer of radicals at lower and higher amount of styrene, respectively. Thus, for the DPNR used in this work, the particle size of the latex was fixed, for which only $1.5 \times 10^{-3} \mathrm{~mol} \mathrm{~g}^{-1}$ dried rubber of styrene is sufficient and a further increase in amount of styrene would not help in increasing the grafting efficiency. Therefore, the highest styrene conversion and grafting efficiency were obtained at $3.5 \times 10^{-5} \mathrm{~mol} \mathrm{~g}^{-1}$ dried rubber of initiator and $1.5 \times 10^{-3} \mathrm{~mol} \mathrm{~g}^{-1}$ dried rubber of monomer, that is above 90 and $70 \%$, respectively. The grafting efficiency is a bit lower than that reported in our previous work. ${ }^{13}$ This is may be due to the difference 


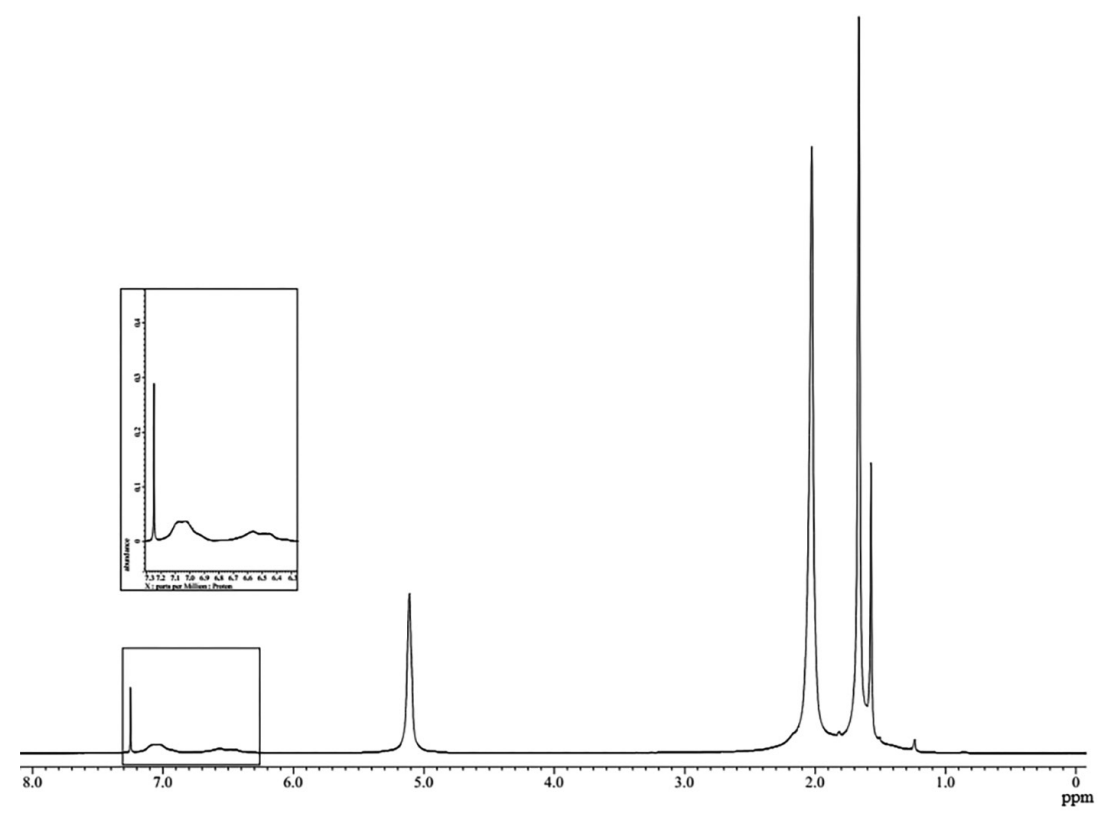

Figure 1. ${ }^{1} \mathrm{H}$ NMR spectrum for DPNR-graft-PS copolymer prepared with $1.5 \times 10^{-3} \mathrm{~mol} \mathrm{~g}^{-1}$ dried rubber of styrene $\left(400 \mathrm{MHz}^{\mathrm{CDCl}}\right)_{3}$.

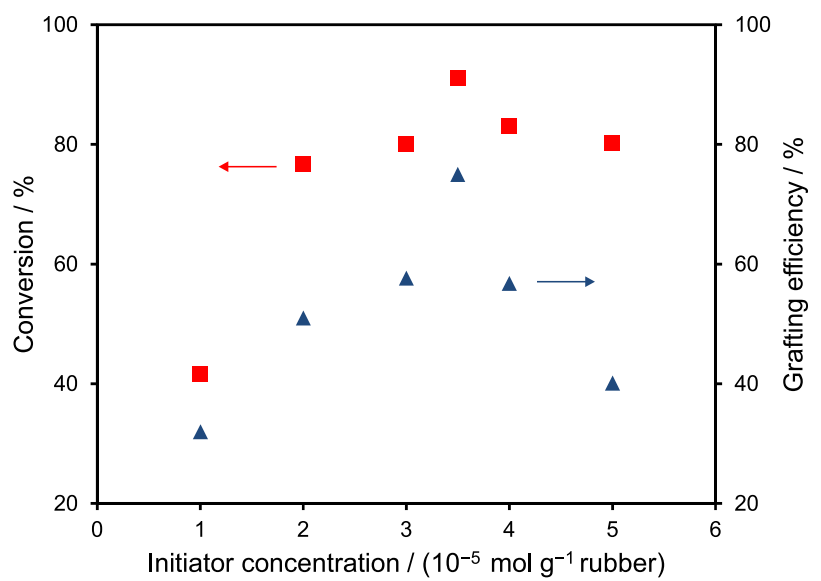

Figure 2. Variation of styrene conversion ( $\square$ ) and grafting efficiency as a function of initiator concentration.

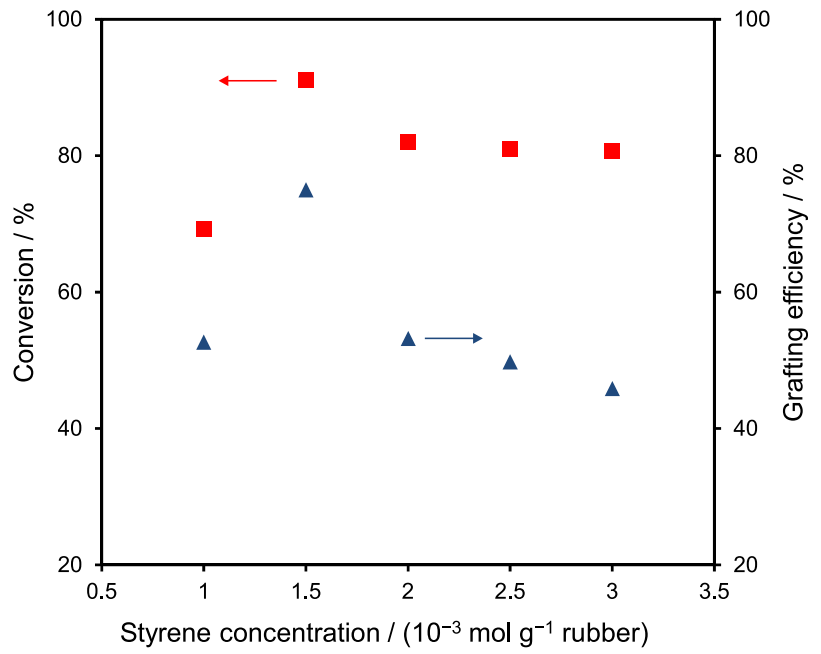

Figure 3. Variation of styrene conversion ( $\square$ ) and grafting efficiency ( as a function of styrene concentration. in the composition of DPNR latex; for instance the nitrogen content, fatty acid content and molecular weight distribution.

Thermal analysis

Thermal properties of DPNR and the graft copolymer were investigated by DSC and TGA as shown in Figures 4, 5 and 6 . The graft copolymer was prepared with $1.5 \times 10^{-3} \mathrm{~mol} \mathrm{~g}^{-1}$ dried rubber of styrene, which is abbreviated as DPNR-graft-PS 1.5.

In the Figure 4, the glass transition temperature $\left(\mathrm{T}_{\mathrm{g}}\right.$ ) of the DPNR was $-63.9{ }^{\circ} \mathrm{C}$ while the $\mathrm{T}_{\mathrm{g}}$ of the DPNR-graft-PS was $-63.14^{\circ} \mathrm{C}$. There was a slight shift in $T_{g}$ of the DPNR and the graft copolymer which is explained to be due to the stiffening or the increasing of the interaction among polar functional groups of the graft copolymer. TGA and differential thermal analyses (DTA) curves of DPNR and the graft copolymer are displayed in Figures 5 and 6, respectively. It can be seen in Figure 5 that the decomposition of DPNR and DPNR-graft-PS were similar to each other. However, the decomposition of DPNR seems to start a little earlier than that of DPNRgraft-PS. In the Figure 6, two decomposition temperatures were observed for DPNR-graft-PS (382.31 and $\left.429.93^{\circ} \mathrm{C}\right)$ and for DPNR (375.27 and $405.79^{\circ} \mathrm{C}$ ). The decomposition temperatures of DPNR-graft-PS are higher than those of DPNR. The higher decomposition temperature is related to the degradation of the graft copolymer. This indicates that the grafting with styrene improved the thermal stability of NR. ${ }^{3}$ 


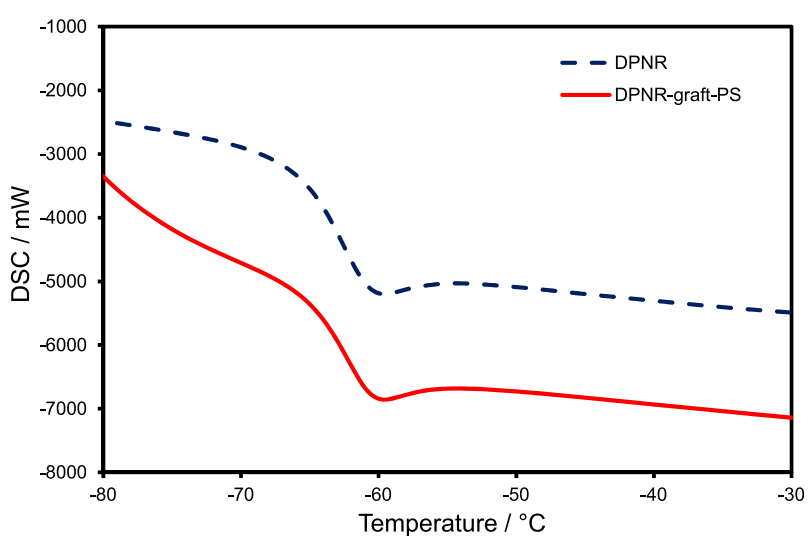

Figure 4. DSC curves of DPNR and DPNR-graft-PS 1.5.

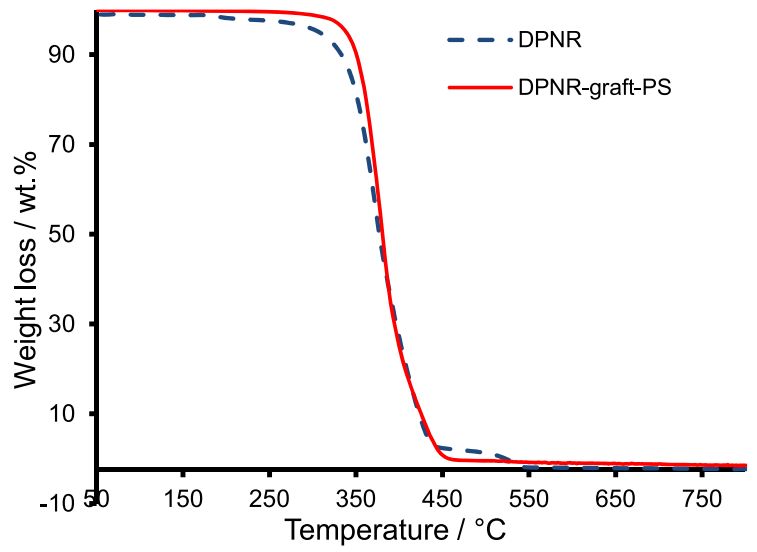

Figure 5. TGA curves of DPNR and DPNR-graft-PS 1.5.

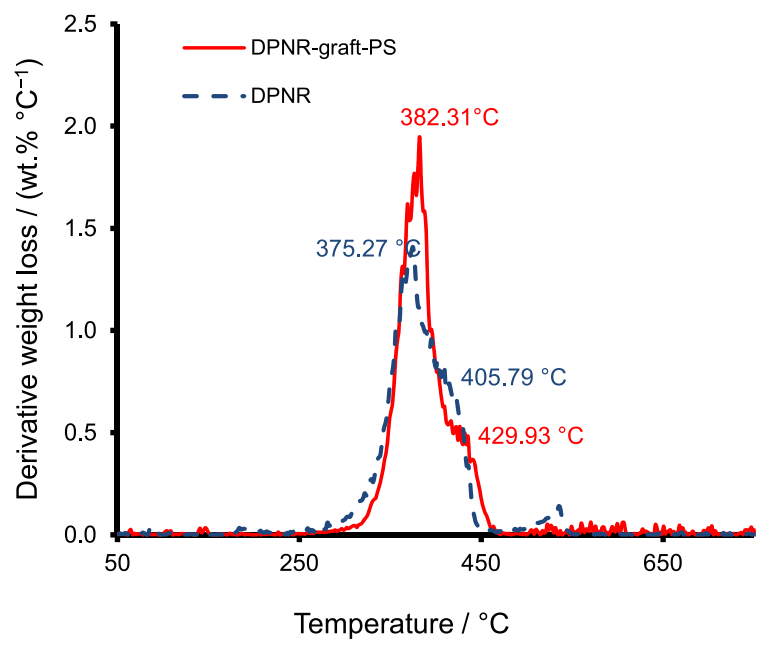

Figure 6. DTA curves of DPNR and DPNR-graft-PS 1.5.

Mechanical properties

The stress-strain curves of unvulcanized rubber are shown in Figure 7. It can be seen that the tensile strength of DPNR was about 4.5 MPa. After grafting of styrene onto DPNR, the tensile strength was increased 4 times, to about $17 \mathrm{MPa}$, in DPNR-graft-PS $1.5 .^{14}$ The significant increase in the tensile strength of DPNR-graft-PS may be explained to be due to the effect of polystyrene layer which is chemically linked to NR particles. The results confirms that styrene was successfully grafted onto NR during graft copolymerization.

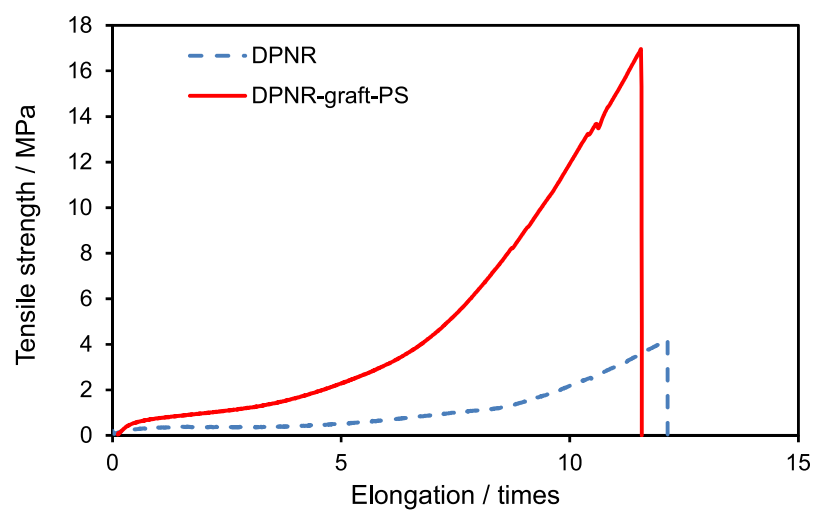

Figure 7. Stress-strain curves of unvulcanized DPNR and DPNR-graftPS 1.5.

The variation of the calculated logarithm of the storage modulus, $\log \mathrm{G}^{\prime}$, as a function of the logarithm of frequency at $30{ }^{\circ} \mathrm{C}$ for DPNR and DPNR-graft-PS 1.5 is presented in Figure 8. As for DPNR, the log G' equaled to 5 , which means the value of storage modulus was $0.2 \mathrm{MPa}$. Meanwhile, for graft copolymer, the value of storage modulus was much higher. It reached to the value of $5 \mathrm{MPa}$, which was 25 times as high as that for DPNR. $^{24}$

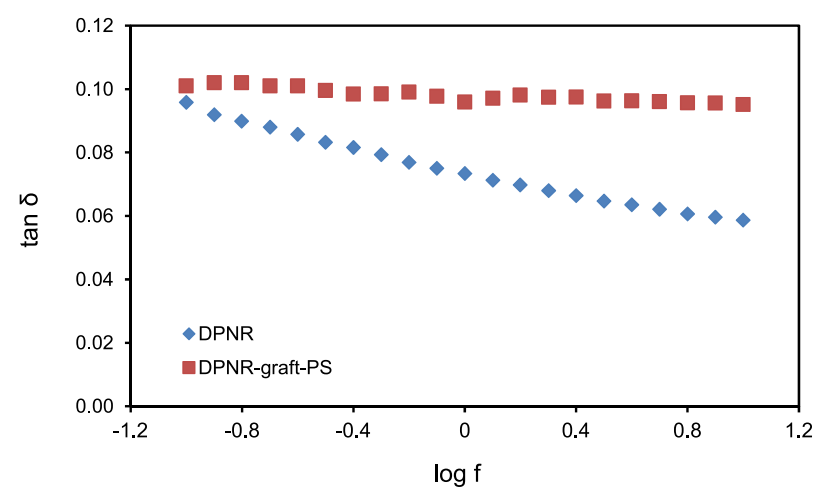

Figure 8. The variation of the calculated logarithm of storage modulus, $\log$ G', as a function of the logarithm of frequency, $\log f$, for DPNR and DPNR-graft-PS 1.5.

The variation of the loss tangent, $\tan \delta$, as a function of the logarithm of frequency for DPNR and DPNR-graft-PS 1.5 is indicated in Figure 9. The loss tangent is defined as the ratio of the loss modulus to the storage modulus. For DPNR, the loss tangent was about 0.1 at a low frequency range. The value decreased with the increasing of frequency. However, for DPNR-graft-PS, the value 
did not change after graft copolymerization and it was approximately similar to that of DPNR at low frequency. ${ }^{24}$

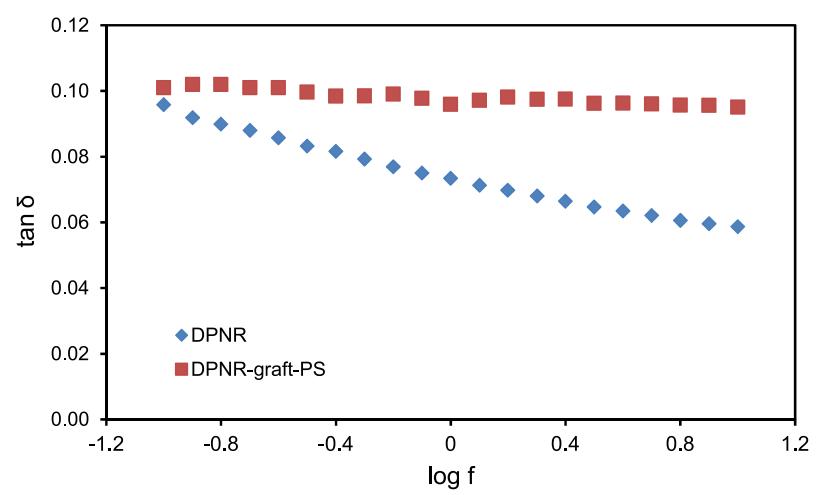

Figure 9. The variation of the loss tangent, $\tan \delta$, as a function of the logarithm of frequency, $\log$ f, for DPNR and DPNR-graft-PS 1.5.

The variation of the $\tan \delta$ as a function of temperature for DPNR and DPNR-graft-PS 1.5 is shown in Figure 10. It is observed that for the DPNR-graft-PS 1.5, the second transition appears at $105{ }^{\circ} \mathrm{C}$ and it is attributed to the grafted polystyrene. From -70 to $30{ }^{\circ} \mathrm{C}$, loss tangent of DPNR-graft-PS was lower than that of DPNR. This also may be due to the effect of polystyrene layer surrounding NR particles. It is important to note that the maximum positions along with a broadening of damping factor peak for DPNR-graft-PS were lower than those of DPNR. This damping behavior is indicative of the interfacial interaction that resulted from the chemical modification.

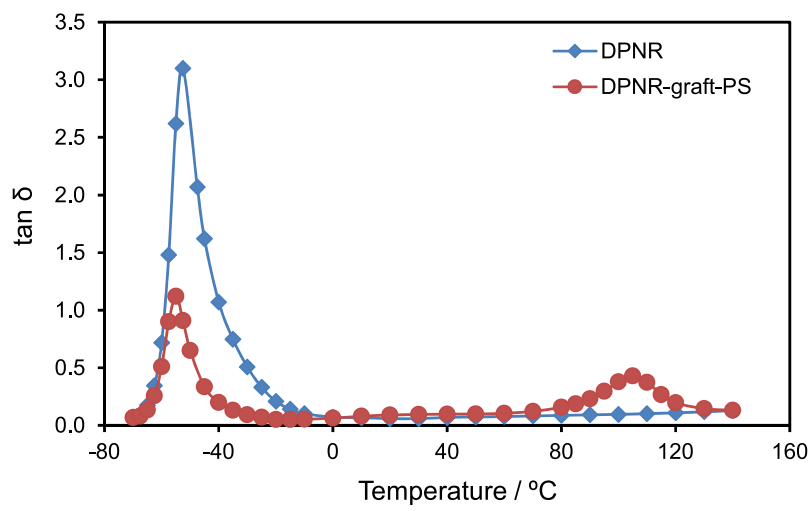

Figure 10. Variation of $\tan \delta$ as a function of temperature for DPNR and DPNR-graft-PS 1.5.

\section{Morphology}

TEM images for DPNR and DPNR-graft-PS 1.5 prepared with $1.5 \times 10^{-3} \mathrm{~mol} \mathrm{~g}^{-1}$ rubber of styrene are shown in Figure 11. In the TEM images (stained with $\mathrm{OsO}_{4}$ ), the dark domain represents $\mathrm{NR}$ and the bright domain represents polystyrene. As can be seen in the TEM image for DPNR-graft-PS, the NR particles were covered with the polystyrene layer of about $30 \mathrm{~nm}$ in thickness. The graft copolymer formed in the present work has a core-shell structure, in which the NR particle as a core is surrounded by polystyrene nano-layer as a shell. The morphology of the graft copolymer in the present work is similar to those presented in the previous works. ${ }^{25,26}$ The formation of chemical linkages after graft copolymerization is proved to play an important role in enhancement of physical properties of graft copolymer.
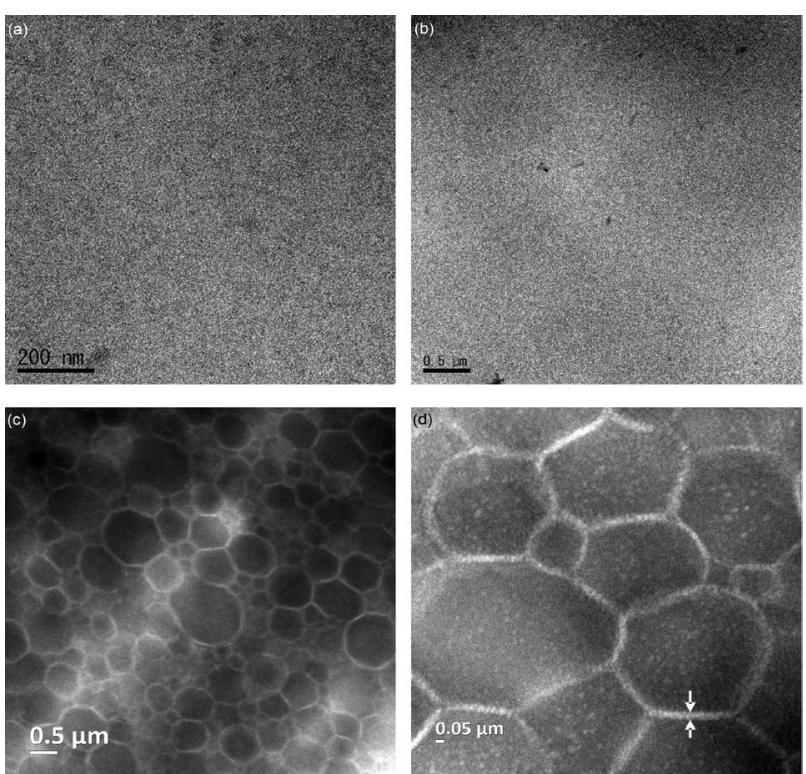

Figure 11. Transmission electron micrographs of DPNR at (a) $\times 5000$ and (b) $\times 20000$ magnification; and graft copolymer at (c) $\times 3000$ and (d) $\times 10000$ magnification.

\section{Conclusions}

The graft copolymerization of styrene onto DPNR was successfully carried out using a redox initiator, in which styrene conversion and grafting efficiency were achieved above 90 and $70 \%$, respectively. The core-shell arrangement was formed in DPNR-graft-PS with $30 \mathrm{~nm}$ in thickness of polystyrene nano-layer. After grafting styrene onto DPNR, the tensile strength of DPNR-graft-PS was about $17 \mathrm{MPa}$, increasing about 4 times from 4.5 MPa of DPNR. The storage modulus of graft copolymer was about 25 times higher than that of DPNR, while its loss tangent was lower. The increase in thermal decomposition temperature of graft copolymer indicated that the graft copolymerization with styrene improved the thermal stability of the DPNR.

\section{Acknowledgments}

This research is funded by Vietnam National Foundation for Science and Technology Development (NAFOSTED) under grant number 104.04-2013.41. 


\section{References}

1. Kroswit, J. I.; Concise Encyclopedia of Polymer Science Engineering; Wiley: London, England, 1990, p. 1015.

2. Mark H. F.; Encyclopedia of Polymer Science Engineering; Wiley: New York, USA, 1970, p. 492.

3. Wongthong, P.; Nakason, C.; Pan, Q.; Rempel, G. L.; Kiatkamjornwong, S.; Eur. Polym. J. 2013, 49, 4035.

4. Benmesli, S.; Riahi, F.; Polym. Test. 2014, 36, 54.

5. Zhong, J. P.; Li, S. D.; Peng, Z.; Yu, H. P.; J. Appl. Polym. Sci. 1999, 73, 2863.

6. Gelling, I. R.; Rubber Chem. Technol. 1985, 58, 86.

7. Mahittikul, A.; Prasassarakich, P.; Rempel, G. L.; J. Appl. Polym. Sci. 2006, 100, 640.

8. Huang, N. J.; Sundberg, D. C.; J. Polym. Sci., Part A: Polym. Chem. 1995, 33, 2533.

9. Huang, N. J.; Sundberg, D. C.; J. Polym. Sci., Part A: Polym. Chem. 1995, 33, 2587.

10. Okieimen, F. E.; Urhoghide, I. N.; J. Appl. Polym. Sci. 2002, $84,1872$.

11. Arayapranee, W.; Prasassarakich, P.; Rempel, G. L.; J. Appl. Polym. Sci. 2002, 83, 2993.

12. Songsing, K.; Vatanatham, T.; Hansupalak, N.; Eur. Polym. J. 2013, 49, 1007.

13. Kawahara, S.; Kawazura, T.; Sawada, T.; Isono, Y.; Polymer 2003, 44, 4527.

14. Fukuhara, L.; Kado, N.; Thuong, N. T.; Loykulant, S.; Suchiva, K.; Kosugi, K.; Yamamoto, Y.; Ishii, H.; Kawahara, S.; Rubber Chem. Technol. 2015, 88, 117.
15. Fukushima, Y.; Kawahara, S.; Tanaka, Y.; J. Rubber Res. 1998, $1,154$.

16. Nakason, C.; Kaesaman, A.; Yimwan, N.; J. Appl. Polym. Sci. 2003, 87, 68 .

17. Sansatsadeekul, J.; Sakdapipanich, J.; Rojruthai, P.; J. Biosci. Bioeng. 2011, 11, 628 .

18. Kawahara, S.; Klinklai, W.; Kuroda, H.; Isono, Y.; Polym. Adv. Technol. 2004, 15, 181.

19. Eng, A. H.; Kawahara, S.; Tanaka, Y.; J. Nat. Rubber Res. 1993, 8, 109.

20. Klinklai, W.; Saito, T.; Kawahara, S.; Tashiro, K.; Suzuki, Y.; Sakdapipanich, J. T.; J. Appl. Polym. Sci. 2004, 93, 555.

21. Kochthongrasamee, T.; Prasassarakich, P.; Kiatkamjornwong, S.; J. Appl. Polym. Sci. 2006, 101, 2587.

22. Yusof, N. H.; Kawahara, S.; Said, M. M. D.; J. Rubber Res. 2008, 11, 97.

23. Phan, N. T.; Onoe, H.; Yamamoto, Y.; Kawahara, S.; Colloid Polym. Sci. 2008, 286, 993.

24. Yusof, N. H.; Kosugi, K.; Fukuhara, L.; Yamamoto, Y.; Kawahara, S.; Colloid Polym. Sci. 2015, 293, 2249.

25. Kawahara, S.; Yamamoto, Y.; Fujii, S.; Isono, Y.; Niihara, K.; Jinnai, H.; Nishioka, H.; Takaoka, A.; Macromolecules 2008, 41,4510 .

26. Kosugi, K.; Sutthangkul, R.; Chaikumpollert, O.; Yamamoto, Y.; Sakdapipanich, J.; Isono, Y.; Kawahara, S.; Colloid Polym Sci. 2012, 290, 1457. 